The relationships between $P_{\mathrm{a}}, P_{\mathrm{m}}$ and $P_{\mathrm{r}}$ will then be as follows.

$$
\begin{aligned}
& P_{\mathrm{m}} \cos \alpha=P_{\mathrm{r}} \sin (\alpha-\phi) \quad \text {. . . . . . . . } \\
& P_{\mathrm{a}}=P_{\mathrm{m}} \sin \alpha+P_{\mathrm{r}} \cos (\alpha-\phi)
\end{aligned}
$$

From these, the corrections $\sigma_{1 \mathrm{~m}}$ and $\sigma_{3 \mathrm{~m}}$ to be deducted from the uncorrected values of axial stress and ambient pressure respectively can be derived.

$$
\begin{aligned}
& \sigma_{1 \mathrm{~m}}=\frac{P_{\mathrm{m}}}{A}(\sin \alpha+\cos \alpha / \tan (\alpha-\phi)-\cos \alpha / \tan \alpha) \quad \text {. . . . . } \\
& \sigma_{3 \mathrm{~m}}=-\frac{P_{\mathrm{m}}}{A}(\cos \alpha / \tan \alpha) \text {. . . . . . . . . . . }
\end{aligned}
$$

$\sigma_{3 \mathrm{~m}}$ is equivalent to the correction included in Pachakis' eqn (10), which is unaffected by this discussion. The reason for expressing $\sigma_{1 \mathrm{~m}}$ and $\sigma_{3 \mathrm{~m}}$ in terms of $P_{\mathrm{m}}$ is that La Rochelle (1967) presents a theoretical expression for this quantity which not only is convenient for use on a computer but also takes such factors as the extension modulus of the rubber membrane and the friction between the rubber membrane and the soil into account. The values of $P_{\mathrm{m}}$ calculated by La Rochelle's (1967) theory after correcting the algebra (La Rochelle, 1970) have, however, to be multiplied by a correction factor of 0.614 in order to enable the deviator stress due to the rubber membrane calculated by Pachakis' theory to fit the experimental value measured by La Rochelle (1967) on a Perspex specimen with ball bearings on the slip plane.

Only in the case of a saturated specimen sheared under undrained conditions will eqn (A3) reduce to an equivalent correction given by Pachakis' theory. In all other cases $\sigma_{1 \mathrm{~m}}$ includes $\phi$ which is to be measured in the triaxial tests, and so has to be calculated by successive approximations.

\title{
REFERENCES
}

La Rochelle, P. (1967). Membrane, drain and area correction in triaxial test on soil samples failing along a single shear plane. Proc. 3rd Panamerican Conf. Soil Mech. 1, 273-293.

La Rochelle, P. (1970). Private communication.

\section{Elastic settlement of a circular raft in adhesive contact with a transversely isotropic medium}

HOOPER, J. A. (1975). Géotechnique 25, No. 4, 691-711.

\section{K. S. Maini, Institut für Grundbau und Bodenmechanik}

While presenting equations for settlement influence factors $I_{w}$, Hooper has referred to a derivation by Wolf (1935) in which the shear modulus was arbitrarily taken as

$$
G=\frac{E_{1} E_{2}}{E_{1}+E_{2}(1+2 \nu)}
$$

Attention is drawn to the fact that such a condition is valid only for the case of $\nu=0$ (or $m=\infty$ ).

It should be pointed out that the value of $G$ should not be arbitrarily taken as Wolf has done, but ought to be based on theoretical considerations as has been done by Jelinek (1948) in his article 'Der Boden als querisotropes Medium'. 
Author's reply to Maini

In the case of a transversely isotropic medium whose axis of elastic symmetry is vertical, the shear modulus in the vertical plane $G_{\mathrm{VH}}$ is one of the five independent elastic constants necessary to define the stress-strain relationships for the material. It follows that analytical solutions in which $G_{\mathrm{VII}}$ is expressed in terms of other elastic constants must be classed as approximate. The solution given by Wolf (1935) is one of several that fall into this category.

\title{
REFERENCES
}

Jelinek, R. (1948). Der Boden als querisotropes Medium. Abhandlung über Bodenmechanik und Grundbau. Forschungsgesellschaft für das Straßenwesen. Berlin: Erich Schmidt Verlag.

Wolf, K. (1935). Ausbreitung der Kraft in der Halbebene und im Halbraum bei anisotropem Material. Z. angew Math. Mech. 15, No. 5, 249-254.

\section{The misuse of SPT $N$ value correlations with Upper Chalk grades}

\author{
LORD, E. R. F. and SMITH, W. E. (1976). Géotechnique 26, No. 1, 217-220.
}

\section{J. P. Dennehy, Ground Engineering Ltd, Boreham Wood}

I would agree with Lord and Smith that there is no substitute for chalk grading by visual inspection. The deficiencies of using the SPT test to infer chalk grade are clearly made in my previous Technical Note and confirmed by my Fig. 1 (Dennehy, 1975). Overall changes in the $N$ value with grade are small because the grades are usually of the same lithology. The $N$ values obtained within a lithology are influenced by chalk grade because of the relative number of discontinuities and the nature of their infill, but there is no pronounced distinction in $N$ values between grades. Thus the lack of a defined change in $N$ value with chalk grade shown by Lord and Smith in their Figs 1 and 2 is only to be expected.

A principal point of the correlation I presented was to show that the relative hardness of the chalk is dependent on lithology and the correlations from lithologies cannot be interchanged. This is illustrated by my Fig. 2 which compares visually observed Upper Chalk grades with Wakeling's (1969) proposed correlation for Middle Chalk, and shows that they do not agree. Lord and Smith misinterpret this figure to mean that the SPT under-estimates the quality of the chalk.

Carter and Mallard (1974) have shown that there is a general trend for an increase in dry density with increasing age. It therefore follows that, in general, SPT $N$ values in chalks of the same grade will be lower in younger chalks. It is also to be noted that in the grading system proposed by Ward et al. (1968) the only difference between grades I and II chalk is in their relative hardness. Grade $I$ is taken to relate specifically to the harder marker bands found within the chalk such as the Chalk Rock. These facts indicate that each fossil zone will have a different density, and consequently a different range of $N$ values would be expected in each. Some recent work by Clayton (1976) has shown this effect.

Although their sample is small, and some of their results are from below the water table, Lord and Smith indirectly confirm this dependence on fossil zone in their Table 3 which shows that $N$ values are less in the Micraster Coranguinum than in the Middle Chalk. These values correspond reasonably with the values quoted by Dennehy in Table 2, given that the latter table also includes younger chalk zones. 